\title{
A Literature Review on Challenges of Virtual Team's Leadership
}

\author{
Hossein Gazor \\ Department of Management and Accounting, Allameh Tabatab'ee University, Tehran, Iran \\ E-mail: hossein.gazor@yahoo.com
}

Accepted: July 17, 2012 Published: August 15, 2012

Doi:10.5296/jsr.v3i2.2247 URL: http://dx.doi.org/10.5296/jsr.v3i2.2247

\begin{abstract}
Virtual teams have emerged seeing that the world has become extremely compound and technological. In this paper, author attempted to address main challenges of virtual team especially in leadership. In this review, it is distinguished that having proper communications and trust between team members can obtain consistent success and reach team goals. A leader in virtual organization should converge all of team elements because of the lack of sound communication among members. Identifying and applying appropriate team leading strategies for a virtual condition will not only raise the value of organizational productivity but will also positively influence on the quality of trust and culture of virtual team members.
\end{abstract}

Keywords: Virtual Team, Leadership, Trust, Communication.

\section{Introduction}

In recent years, activities in all types of organizations have become increasingly more global, competition from both foreign and domestic sources has grown dramatically, and there has been a continued shift from production to service/knowledge-based work environments (Townsend et al ,.1998). Advances in information and communication technology have enabled a faster pace of change than in the past and have created jobs that are increasingly more complex and dynamic (Hunsaker \& Hunsaker, 2008). For facing with this wide and dramatically world changing, organizational structures, communications, strategies, processes, policies, and so on, must turn more flexible. Virtual teaming is a new way of managing and organizing work that allows people to work together even though they are geographically separated. People working in virtual teams use technology to communicate with each other rather than working face-to-face or traveling to meetings. Virtual teaming, where people work together apart, has been found to be very different to traditional teaming, where people work together (The Virtual Teaming Association, 2003). 
Virtual teams are groups of geographically and/or organizationally dispersed co-workers that are assembled using a combination of telecommunications and information technologies to accomplish an organizational task (Malhotra et al., 2007). Organizations use virtual teams for myriad functions, ranging from cross-functional project teams to task forces and line management (Brown et al., 2007). Virtual teams allow organizations to access the most qualified individuals for a particular job regardless of their location, enable organizations to respond faster to increased competition, and provide greater flexibility to individuals working from home or on the road (Hunsaker \& Hunsaker, 2008). Of course, Virtual teamwork is more complex than working face-to-face (Heimer and Vince, 1998) and site specific cultures and lack of familiarity are reported to be sources of conflict (Hinds and Bailey, 2003). However, leadership issues now will become increasingly high essential for virtual team because these characteristics that are cited aforementioned. Leader of virtual team should know about whole of differences existing between this kind of and conventional team. Identifying these distinctions and knowing on dimensions of virtual teams, a leader can encourage team members to gain best performance and to contribute to main objectives of team.

\section{Literature Review}

\subsection{Dimensions Of Virtual Teams}

Virtual teams have several features that differentiate them from conventional teams. These dimensions cause many advantages and disadvantages (Bergiel et al., 2008) for organizations that deploy virtual teams to perform tasks. Attention to virtual teams dimensions help organizations to execute their processes better than before. Trust, communication, leadership, goal setting and technology all emerge as factors vital to the formation of a successful virtual team (Barczak et al., 2006; Brennan and Braswell, 2005; Couzins and Beagrie, 2005). In this paper, "technology" will address in "communication" subtitle. Considering to literature (Oertig and Buergi, 2006; Holton, 2001; Gatlin-Watts, 2007; Pauleen and Yoong, 2001; Brown et al., 2007, Gibson and Cohen, 2003, Jackson, 1999), author believes that culture also is a vital element of any conventional or virtual team. This paper will attempt to proceed main features of virtual teams that can illustrate different sides of them.

\subsubsection{Spatial Distances}

The most important feature of virtual teams is that they cross boundaries of space (Hunsaker \& Hunsaker, 2008). While the members of traditional teams work in close proximity to one another, the members of virtual teams are separated, often by many miles or continents (Pape, 1997; Townsend et al., 1996). Even if members of virtual teams have excellent ability in speaking languages of other members of team, they don't tend to relate with together in face-to-face mode, rather they utilize technologies for example, email, videoconference, telephone, webcam, internet, and so on to liaise. As mentioned above, Snyder (2003) pointed 
out that even when employees have good language skills, they naturally interpret written and verbal communication through the filter of their own culture. People who are distant from one another are less likely to share information freely and less likely to pay attention to information from their distant team members. Thus, members of virtual teams can be expected to have more difficulty developing a shared group identity and attending to the information that flows among team members. Such a lack of attention may reduce shared understanding in virtual teams (Gibson and Cohen, 2006). Teams with more geographically separation have more diversity in perspectives and attitudes. For example, Karnoe (1995) observed that Danish and American workers used different paradigms for understanding problems and potential solutions and attributed these differences to disparities in local routines and behavioral norms. Distant teams also are more likely to be demographically dissimilar than collocated teams (Gibson and Cohen, 2006).

Virtual teams allow organizations to become more flexible, adaptive, and responsive by enabling them to cross boundaries of space, but the issues of cultural context need to be recognized.

\subsubsection{Culture}

All teams experience challenges in culture, logistics, communication, and so on, but with virtual teams, those challenges are exacerbated by not being in the same room or locale (Brown et al., 2007). Gatlin-Watts et al. (2007), with exploring multicultural virtual teaming project implementation identified that the virtual projects remove travel barriers and promote a virtual exchange of cultural information between their students and students abroad that results in a better understanding of cultures. Culture has invisible (e.g. Beliefs, Values, Perceptions, attitudes, etc.) and visible (e.g. Communication styles, Response to conflict, Decision making styles, etc.) dimensions that is important to identified by leaders of teams. People from different countries and cultures will have their own view of the world and ways of doing things. (As an example, try asking each person to define 'team' and see what you get.) When setting up your virtual team, it's easy to overlook this and assume that we're all the same. In so doing, you may unknowingly cause great offence to others (Fleming, 2006). Oertig and Buergi (2006) in investigating cross-cultural project stressed to take into account the value of ongoing investment in language and intercultural communication training. They concentrated that training is particularly important for new members of project teams working on different continents, to help reduce potential distrust, and allow teams to get more quickly and work together efficiently.

\subsubsection{Communication}

When people communicate face-to-face, about 70 percent of the information exchanged is nonverbal. This nonverbal information is lost when the people communicating cannot see or hear each other, but must rely on written exchanges (Brown et al., 2007). Humans are in communication era. Information play key role to come over environmental uncertainties. 
Having more advanced communication technologies and accessing to rare information bring about that organization gain constant competitive advantages. In recent years of business, many technologies are introduced to managers. Although e-mail is probably the most common, other more complex and interactive communication technologies, such as videoconferencing, groupware, and project management software, are growing in popularity (Geber, 1995). These technologies allow to members of virtual teams to communicate with other in separate and far locations very easily. They can share data and information with these primarily technologies. While most virtual team members have a positive experience working across space and time, the biggest area of complaint involved communication problems (Grenier and Metes, 1995) for example lack of project visibility, difficulty in contact, and technology constraints (Hunsaker \& Hunsaker, 2008). Virtual teams must be vigilant about closing the feedback loop, being proactive about communication, avoiding jumping to conclusions, establishing a clear escalation path, and maintaining a sense of humor (Brown et al., 2007). Individuals from different national cultures vary in terms of their communication styles and group behaviors, which include the motivation to seek and disclose individuating information and the need to engage in self-categorization (Gudykunst, 1997). Anderson et al. (2007) suggest that the "effective use of communication, especially during the early stages of the team's development, plays an equally important role in gaining and maintaining trust". Virtual team members must learn to excel as active communicators. The success of the team depends on the ability of team members to exchange information in face of the challenge of time and place (Bergiel et al., 2008). Communication technologies have limitations that can easily lead to misinterpretation. They cannot provide the same richness as face-to-face interaction. Because of delays in transmission and the lack of social and nonverbal cues, communication technologies can interfere with open communication, knowledge sharing, and the ability of teams to identify and resolve misunderstandings (Gibson and Cohen, 2006). As stressed in literature, knowledge sharing is very momentous element of trust building in virtual teams. Knowledge sharing is less likely to take place when people must type out complex ideas or try to hold a telephone conversation for an extended period of time. Knowledge sharing also takes place less often over mediated technologies because people have more difficulty sharing complex knowledge. Although basic information may be shared, there is less elaboration on the meaning of the information, and therefore less understanding is reached. (Gibson and Cohen, 2006). The leaders of virtual teams must work cooperatively with their team members and establish strict guidelines concerning not only "what" and "when" to communicate but also "how" to communicate (Ojala, 2004). In building a culture of familiarity relationships, trust is a key to enhancing the quality of communication (Bergiel et al., 2008).

\subsubsection{Trust}

Trust, then, is efficient. You save yourself a lot of time and trouble by being able to rely on someone's word (Arrow, 1974). One of the key issues in virtual teams is to develop trust. In face-to-face relations, trust is built simpler than virtual mood. Handy (1995) pointed out this explicitly: 
If we are to enjoy the efficiencies and other benefits of the virtual organization, we will have to rediscover how to run organizations based more on trust than on control. Virtuality requires trust to make it work. Technology on its own is not enough.

Trust building is same a core for formatting a team, especially for initialing point. Trust is the foundation of all successful relationships, especially in team building; in fact, it must exist in all of them. It is often the result of team members knowing that all people in a team can be counted on to complete their assigned tasks. Trust is a vital factor especially for virtual teams because of the lack of personal face-to-face interaction (Bergiel et al., 2008). Establishing trust is fundamental to the successful formation and growth of any new work team (Glacel, 1997; Awe, 1997; Senge et al., 1994). Joinson (2002) offers sentences on trust:

Getting a team together physically is perhaps the best step a manager can take to enhance communication and trust between its members and minimize the sense of isolation. Even if teams can't meet on a regular basis, an initial meeting will help members understand who they're working with and strengthen their connection. Physical meetings aren't always possible, particularly for short-term or on-the-spot projects. Even so, virtual teams can meet each other through teleconferences or videoconferences that allow individual voices and personalities to come through.

\subsection{Virtual Team Leadership}

A 1985 study counted over 300 definitions of leadership (Bennis and Nanus, 1985). Berge (1996) proposes leadership as mediation in order to overcome the variety of task and relational problems that may be encountered by a group. In virtual teams, leaders are often the nexus of the team, facilitating communications, establishing team processes, and taking responsibility for task completion (Duarte and Tennant-Snyder, 1999). The importance of leadership in virtual teams is noted in the practitioner literature (Lipack and Stamps, 1997; O'Hara-Devereaux and Johanson, 1994), and recent research (kayworth and leidner, 2001) has begun to look at leadership issues in virtual teams (Pauleen, 2003).

In traditional teams involving face-to-face interaction, leadership has a strong influence on team performance and individual team members' satisfaction (Bass, 1990; Hackman, 1990b). Leaders always are people that can influence on other behavior, attitude, and perspective, and in fact, they can drive team to obtain its objectives. Leaders can accelerate tasks distribution between team members and with this, they produce better performance. By assigning tasks to individuals with the skills, knowledge, and abilities to perform them best, a leader can greatly increase team effectiveness and efficiency (McGrath, 1984). Leaders inspire others through communication of a vision for the team's work (Conger and Kanungo, 1988). Having clear goals and objectives is critical to effective team functioning, and leaders can facilitate team members' understanding of objectives (Hackman, 1990b). Effective team leaders also network with individuals inside and outside the team (Tyran et al., 2003). Another important 
skill is data splitting, defined as filtering through the information gathered by the team and determining what is important and what is not (Barge, 1996). For traditional teams, trust in a leader's ability to facilitate team task and relationship interaction effectively has been found to be a critical factor in achieving the consensus necessary for a leader to emerge (Bass, 1990). In examining the importance of trust in teams and team leaders, Tyran et al (2003) found it useful to categorize trust into three types (McAllister, 1995; Mayer et al., 1995): Role performance trust, Altruistic behavior, and Affective bond trust. In addition to trust issues, leadership style has been found to play a role in team success (Tyran et al., 2003). One well-known model of leadership is transformational leadership, which involves developing a strategic vision and then communicating that vision so that followers are motivated to work toward achieving the goals associated with it (Conger and Kanungo, 1998) Transformational leaders know their teammates and inspire and motivate to transform the members of the team to see the team's vision and the organization's vision as their own (Bass and Avolio, 1994).

\subsection{Leadership Challenges Of Virtual Teams}

Virtual teams offer high flexibility and other potential benefits, but they also create numerous leadership challenges (Hunsaker \& Hunsaker, 2008). Virtual teams face particular challenges involving trust, communication, deadlines, and team cohesiveness (Jarvenpaa, 1998; Kitchen and McDougall, 1999; Lipnack and Stamps, 2000; Robey et al., 2000; Warkentin et al., 1999). Cascio (2000) states that there are five main disadvantages to a virtual team: lack of physical interaction, loss of face-to-face synergies, lack of trust, greater concern with predictability and reliability, and lack of social interaction. Gibson and Cohen (2006) mentioned several challenges that occur in virtual teams. Those are Technology Failures, Communication Mishaps, Dysfunctional Conflict, Inefficient Work Processes, and Challenges to Support Systems. Gould (1997) mentions also pitfalls of the virtual teams: lack of individual recognition, celebrations of team accomplishments, lack of project visibility, the constraints of technology and lack of trust.

Communication is a challenge in virtual teams. The issues include the lack of non-verbal cues, the inability to take advantage of incidental meetings and learning (informal discussion in the mail room), difficulty engaging in spontaneous written communication, and insufficient attention to socio-emotional issues (Hron et al., 2000; Jarveenpaa, 1998; Lipnack and Stamps, 2000; Warkentin et al., 1999). The challenges of communication technology make more difficult for leaders to manage virtual teams. Because these technologies may catch damage suddenly and it cut off relations among members; this diminish productivity. State-of-the-art communications technology can boost the capability of teams to collaborate but will not replace for team growth. In this case, leader can play a critical role for team. He/she should transform a tool for communication between members in full calmness.

Sometimes, members themselves may be a problem in communication process. For example, information sharing is one of the vital elements of any team. However, some members refuse information and knowledge sharing among team. Again, team leader must call members to 
collaboration with together till creates harmony and consensus sensation. A recent study of Oracle Corporation and a group of experienced executive leaders focused on the characteristics that executive leaders working within a complex environment deemed as important to being an effective leader (Hanson ,2007). One of the main challenges that emerged from the study was" providing clear direction and being able to effectively connect with virtual team members distributed across time zones “(p. 74).

There are the two primary leadership functions in virtual teams: performance management and team development (Bell and Kozlowski, 2002). The challenge for virtual teams is that these functions must be accomplished by leadership substitutes and by distributing the functions to the team itself (Hunsaker \& Hunsaker, 2008). Virtual team leaders need to distribute facets of these functions to the team and making it more of a self-managing team. Leaders will need to establish a procedure that members can control their own performance Virtual teams' leaders should extremely observe environmental changes and evolutions, because these can impact on team outcomes. Virtual team members need to commit greatly to the team and need to create consistency; in fact, these are conducted by excellent leadership.

When is asked this question: "How do leaders of virtual teams monitor team member's performance and progress toward task accomplishment?", one can answer, as mentioned above, leaders in virtual teams can generate solidarity and unity sense between members. When members are committed to the team objectives, especially long-term goals that bring about successes of whole of team, they are persuaded to pursue team's ideals spontaneously.

How one creates trust within a team of individuals working across distance, time zones, cultures and professional disciplines is a challenge that an increasing number of organizational leaders will face. As social beings, face-to-face interaction will continue to play a very important role in our work relationships regardless of how virtual our environment may become. As such, a wise virtual team leader will also seek to build opportunities for face-to-face meetings into virtual team work whenever possible as a means of enhancing team understanding and accelerating intra-group bonding. Certainly, a wise leader will always employ a face-to-face meeting to resolve a serious team crisis or conflict, even if this face-to-face opportunity must, by necessity of geography, employ a virtual medium like videoconferencing (Holton, 2001).

Jarveenpaa (1998) notes several factors that may negatively influence trust in global virtual teams. These include time, distance, culturally diverse and globally spanning members, and the reliance on computer mediated technology. In a virtual team, as mentioned above, where many of the conventional ways are absent, the significance of trust building is tremendously decisive. Five things a leader should do to boost trust in dispersed operations using virtual teams, are represented by Hunsaker and Hunsaker (2008). These are: (1) Create face time, (2) Set goals and expectations, (3) Provide ongoing feedback, (4) Show-case team members' competence, and (5) Foster cultural understandings. 


\section{Conclusion}

This paper was written to review leadership challenges of virtual team because as above-mentioned challenges that may occur in virtual environment, leaders role will become increasingly fundamental. All of us need to find out importance of virtual team in today's World business, and maybe any of us will work in a virtual team in coming days. Today's trade requires to revision in long-established methods and mechanisms in order to achieve higher productivity and competitive advantages. Although, there may exist some defects in team structure and processes, but excellent leadership resolves these with its resourcefulness and ingeniousness. Regard to paper, author represents following recommendations for leaders. Building cordial relationship with others can prevent any feasible dispute. To raise whole perception, leaders should scatter information and knowledge between members. Dou to member to perform enthusiastically their own tasks, it is better that leaders create convergence among members and team objectives. It is much better that total goals cover individual objectives. They should be honest with members, especially when a dilemma is happened and to select transformational leadership style. It is reasonable that they learn about modern communication technologies; because replacing with old versions as soon as possible, and finally, leaders can set face-to-face meeting as possible as for members; this can generates more recognition within members and decrease probable conflicts.

\section{References}

Anderson, A.H., McEwan, R., Bal, J. and Carletta, J. (2007), "Virtual team meetings: an analysis of communication and context", Computers in Human Behavior, 23 (5), 2558-80.

Arrow, K. (1974), The Limits of Organisation, WW Norton, New York, NY.

Awe, S. (1997), "Trust in the balance: building successful organizations on results, integrity, and concern", Library Journal, 122 (9), 84.

Barczak, G., McDonough, E. and Athanassiou, N. (2006), "So you want to be a global project leader?", Research Technology Management, 49 (3), 28-35.

Barge, J. K. (1996 ), "Leadership Skills and the Dialectics of Leadership in Group Decision Making.” In R. Y. Hirokawa and M. S. Poole (eds.), Communication and Group Decision Making. (2nd ed.) Thousand Oaks, Calif.: Sage

Bass, B. M. (1990). Bass and Stogdill's Handbook of Leadership. New York: Free Press.

Bass, B. M., and Avolio, B. (1994). Improving Organizational Effectiveness Through 


\section{Macrothink}

Transformational Leadership. Thousand Oaks, Calif.: Sage.

Bell, B.S. and Kozlowski, S.W.J. (2002), "A typology of virtual teams: implications for effective leadership”, Group and Organization Management, 27 (1), March, 14-49.

Bennis, W.G. and Nanus, B. (1985), Leaders: The Strategies of Talking Charge, Harper Collins, San Francisco, CA.

Berge, Jk. (1996), "leadership skills and the dialectics of leadership in group decision making", in Hirokawa, R,Y. and poole, M.S. (Eds), Communicat ion and Group Decision Making, Sage, Thousand Oaks, CA, 301-42.

Bergiel, B.J., Bergiel, E.B., and Blasmeier, P.W. (2008), Nature of virtual teams: a summary of their advantages and disadvantages, Management Research News, 31 (2), 99-110.

Brennan, M. and Braswell, P. (2005), "Developing and leading effective global teams", Chief Learning Officer, 4 (3), 44-8.

Brown, M. K., Huettner, B. and James-Tanny. C., (2007). Managing virtual teams : getting the most from wikis, blogs, and other collaborative tools. Wordware Publishing, Inc. Texas. USA.

Cascio, W.F. (2000), "Managing a virtual workplace", Academy of Management Executive, 14 (3), 81-90.

Conger, J., and Kanungo, R. (1988). Charismatic Leadership in Organizations. Thousand Oaks, Calif.: Sage.

Couzins, M. and Beagrie, S. (2005), "How to. . . successfully manage remote teams", Personnel Today, 27.

Duarte, N. and tenant, Snyder, N. (1999), Mastering Virtual Teams: strategies, Tools, and Techniques that succeed, Jossey-Bass, San Francisco, CA.

Fleming, B. L. (2006). THE VIRTUAL TEAMS POCKETBOOK, Management Pocketbooks Ltd., U.K.

Gatlin-Watts, R., Carson, M., Horton, J., Maxwell, L., and Maltby, N. (2007). A guide to global virtual teaming. Team Performance Management. 13(1/2), 47-52.

Geber, B. (1995), "Virtual teams”, Training, 32 (4), 36-40. 


\section{Macrothink}

Journal of Sociological Research

ISSN 1948-5468

2012, Vol. 3, No. 2

Gibson, C. B., and Cohen, S. G. (2006), Virtual Teams That Work Creating Conditions for Virtual Team Effectiveness, John Wiley \& Sons, Inc. San Francisco. USA.

Glacel, B.P. (1997), 'Teamwork's top ten lead to quality", The Journal for Quality and Participation, 20 (1), 12-17.

Gould, D. (1997), “Leading virtual teams”, Boeing Manager Magazine, May, 20-6.

Grenier, R. and Metes, G. (1995), Going Virtual: Moving Your Organization into the 21st Century, Prentice-Hall, Upper Saddle River, NJ.

Gudykunst, W. (1997), "Cultural variability in communication", Communication Research, 24 (4), 327-48.

Hackman, J. R. Groups That Work (and Those That Don't). San Francisco: Jossey-Bass, $1990 \mathrm{~b}$.

Handy, C. (1995), "Trust and the virtual organization”, Harvard Business Review, 73 (3), $40-50$.

Hanson, K.S. (2007), "Emerging elements of leadership in a complex system: a cognitivist approach", EdD doctoral dissertation, San Diego State University/University of San Diego, San Diego, CA.

Heimer, C. and Vince, R. (1998), "Sustainable learning and change in international teams: from imperceptible behaviour to rigorous practice", Leadership \& Organization Development Journal, 19 (2), 83-8.

Hinds, P.J. and Bailey, D.E. (2003), "Out of sight, out of sync: understanding conflict in distributed teams", Organization Science, 14 (6), 615-32.

Holton, J.A., (2001), Building trust and collaboration in a virtual team, Team Performance Management: An International Journal. 7 (3/4) . 36 \pm 47.

Hron, A., Hesse, F.W., Cress, U. and Giovis, C. (2000), "Implicit and explicit dialogue structuring in virtual learning groups", British Journal of Educational Psychology, 7 (1), 53-64.

Hunsaker, P. and Hunsaker, J., (2008). "Virtual teams: a leader's guide", Team Performance Management, 14 (1/2), 86-101.

Jackson, P., (1999). Virtual Working Social and organisational dynamics. Routledge, London and New York. 
Jarvenpaa, S.L. (1998), "Communication and trust in global virtual teams", Journal of Computer Mediated Communication, 3 (4), 165-98.

Joinson, C. (2002), “Managing virtual teams”, HR Magazine, 47(6), 69-73.

Karnoe, P. (1995). Competence as Process and the Social Embeddedness of Competence Building. Academy of Management BEST PAPERS PROCEEDINGS. 55th Annual, Meeting, Vancouver, Canada August 6-9.

Kayworth, T.R. and Leidner, D.E. (2001), "leadership Effectiveness in Global Virtual Teams", Journal of Management Information Systems, 18 (3), 7-40.

Kitchen, D. and McDougall, D. (1999), "Collaborative learning on the internet", Journal of Educational Technology Systems, 27 (3), 245-58.

Lipnack, J. and Stamps, J. (1997), Virtual Teams: Reaching Across Space, Time, and organizational Boundaries, John Wiley and Sons.

Lipnack, J. and Stamps, J. (2000), Virtual Teams: People Working across Boundaries with Technology, 2nd ed., John Wiley \& Sons, New York, NY.

Malhotra, A., Majchrzak, A. and Rosen, B. (2007), "Leading virtual teams", Academy of Management Perspective, 21 (1), 60-70.

Mayer, R. C., Davis, J. H., and Schoorman, F. D. (1995). "An Integrative Model of Organizational Trust.” Academy of Management Review, 20 (3), 709-734.

McAllister, D. (1995). "Affect- and Cognition-Based Trust as Foundations for Interpersonal Cooperation in Organizations.” Academy of Management Journal, 36 (1), 24-59.

Oertig, M. and Buergi, T., (2006). The challenges of managing cross-cultural virtual project teams.Team Performance Management. 12 (1/2), 23-30.

O'Hara-Devareaux, M. and Johnsen, S. (1994), Global Work: Bridging Distance, Culture, and Time, Jossey-Bass, San Francisco, CA.

Ojala, M. (2004), “Being virtual”, Online, 28 (3), 5-8.

Pape, W.R. (1997), “Group insurance: virtual teams can quickly gather the knowledge of even far-flung staff”, Inc. 19 (9), 29-31. 


\section{Macrothink}

Journal of Sociological Research

ISSN 1948-5468

2012, Vol. 3, No. 2

Pauleen, D.J. (2003), Leadership in global virtual team: an action learning approach, Leadership \& Organization Development Journal, 24 (3), 153-162.

Pauleen, D.J., Yoong, P., (2001). Facilitating virtual team relationships via Internet and conventional communication channels, Internet Research: Electronic Networking Applications and Policy. 11 (3), 190 \pm 202

Robey, D., Koo, H.M. and Powers, C. (2000), "Situational learning in cross-functional virtual teams", Technical Communication, 47(1), 51-66.

Senge, P., Kleiner, A., Roberts, C., Ross, R.B. and Smith, B.J. (1994), The Fifth Discipline Fieldbook: Strategies and Tools for Building a Learning Organization, Doubleday, New York, NY.

Snyder, B. (2003), "Teams that span time zones face new work rules", Stanford Business Magazine, May, 3-15.

Townsend, A.M., DeMarie, S.M. and Hendrickson, A.R. (1996), “Are you ready for virtual teams?", HR Magazine, 41 (9), 122-7.

Townsend, A.M., DeMarie, S.M. and Hendrickson, A.R. (1998), "Virtual teams: technology and the workplace of the future", Academy of Management Executive, 12 (3), 17-29.

Tyran, K.L., Tyran, C.K., Shepherd, M. (2003), Exploring Emerging Leadership in Virtual Teams, in Gibson, C.B. and Cohen, S.G. (eds) Virtual Teams That Work, John Wiley \& Sons, San Francisco, CA. pp. 183-195

Virtual Teaming Association (2003), “Announcement and call for expressions of interest", updated version, July, available at: www.knowab.co.uk/vta/

Warkentin, M., Sayeed, L. and Hightower, R. (1999), "Virtual teams versus face-to-face teams", in Kendall, K.E. (Ed.), Emerging Information Technologies Improving Decisions, Cooperation, and Infrastructure, SAGE Publications, Thousand Oaks, CA, pp. 241-62. 